\title{
Numerical Derivation of Buckling Knockdown Factors for Isogrid-Stiffened Cylinders with Various Shell Thickness Ratios
}

\author{
Han-Il Kim, ${ }^{1}$ Chang-Hoon Sim, ${ }^{1}$ Jae-Sang Park ${ }^{D},{ }^{1}$ Keejoo Lee, ${ }^{2}$ Joon-Tae Yoo, ${ }^{3}$ \\ and Young-Ha Yoon ${ }^{3}$ \\ ${ }^{1}$ Department of Aerospace Engineering, Chungnam National University, Daejeon 34134, Republic of Korea \\ ${ }^{2}$ Small Launcher Team, Future Launcher R\&D Program Office, Korea Aerospace Research Institute, \\ Daejeon 34133, Republic of Korea \\ ${ }^{3}$ Launcher Structures and Materials Team, Korea Aerospace Research Institute, Daejeon 34133, Republic of Korea
}

Correspondence should be addressed to Jae-Sang Park; aerotor@cnu.ac.kr

Received 27 December 2019; Accepted 18 April 2020; Published 11 May 2020

Academic Editor: Enrico Cestino

Copyright (c) 2020 Han-Il Kim et al. This is an open access article distributed under the Creative Commons Attribution License, which permits unrestricted use, distribution, and reproduction in any medium, provided the original work is properly cited.

This study is aimed at providing a numerical derivation of the shell knockdown factors of isogrid-stiffened cylinders under axial compressive loads. The present work uses two different analysis models such as the detailed model with modeling of numerous stiffeners and the equivalent model without modeling of stiffeners for isogrid-stiffened cylinders. The single perturbation load approach is used to represent the geometrically initial imperfection of the cylinder. Postbuckling analyses using the displacement control method are conducted to calculate the global buckling loads of a cylinder. The shell knockdown factor is numerically derived using the obtained global buckling loads without and with the initial imperfection of the isogrid-stiffened cylinder. The equivalent model is more efficient than the detailed model in terms of modeling time and computation time. The present knockdown factor function in terms of the shell thickness ratio (radius to thickness) for the isogrid-stiffened cylinder is significantly higher than NASA's knockdown factor function; therefore, it is believed that the present knockdown factor function can facilitate in developing lightweight launch vehicle structures using isogrid-stiffened cylinders.

\section{Introduction}

A thin cylinder is the most important structural element for space launch vehicles. However, it is extremely vulnerable to axial compressive loads. Therefore, in general, numerous stiffeners are used in both the axial and circumferential directions of the thin cylinder to improve its stiffness and strength. The stiffeners are usually arranged in a grid form, such as the orthogrid- and isogrid-stiffened systems (Figure 1) or in a latticed structure [1-3]. The isogrid-stiffened system includes a lattice of intersecting ribs, which form an array of equilateral triangles, as illustrated in Figure 1(b), and it provides the isotropic behaviors of the stiffened structure while improving the buckling load of the cylindrical structure. Therefore, the isogrid-stiffened cylinder is frequently used in the propellant tanks and intertanks of space launch vehicles.
The buckling load of a cylindrical structure is an essential factor in the structural design of launch vehicles. However, the measured buckling load is usually lower than the value calculated by means of linear buckling analysis. Among the various reasons for this discrepancy between the linear buckling analysis and test, the initial imperfection of the thin-shell structure is considered the most important. The buckling knockdown factor has been introduced to reduce appropriately the predicted buckling load using linear analysis. The knockdown factor is defined as the ratio between the global buckling loads of a thin-shell structure without and with initial imperfection. NASA provided the lower bound of the knockdown factors of the cylindrical structure (Figure 2, [4]) using data measured in buckling tests of cylinders from the 1930s to 1960s. Therefore, this buckling design criteria (NASA's the lower bound of knockdown factors) cannot consider the modern manufacturing technologies 


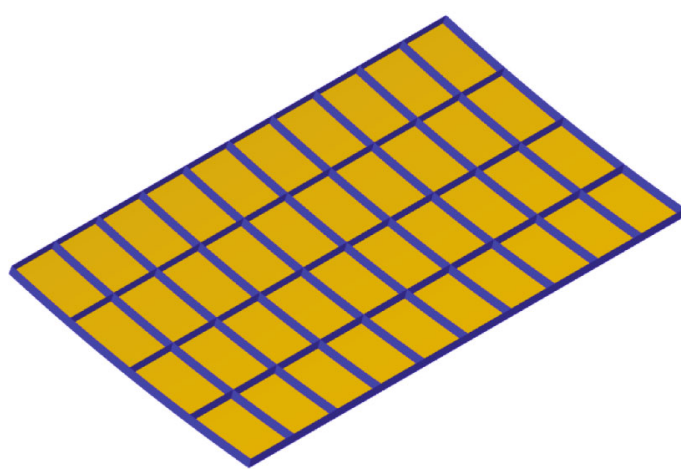

(a) Orthogrid system

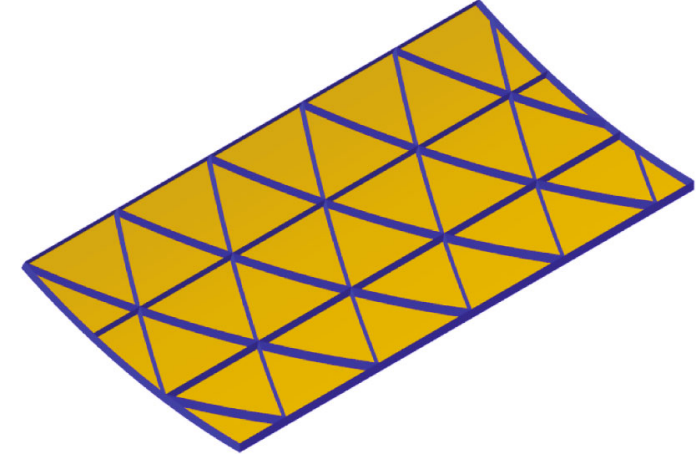

(b) Isogrid system

Figure 1: Grid-stiffened systems.

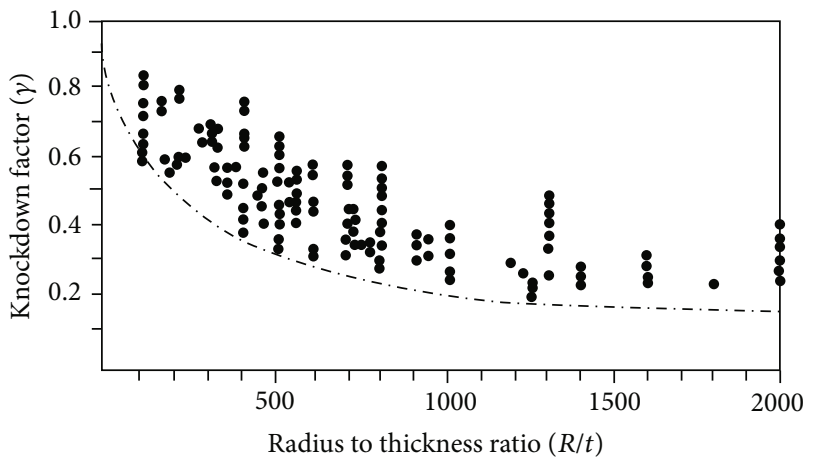

Figure 2: NASA's lower bound of knockdown factors [4].

and advanced materials for launch vehicle structure; as a result, the launch vehicle structure is conservatively designed, that is, overweight designed. The manufacturing precision has a significant influence on the geometrically initial imperfection of a cylinder, and the imprecise manufacturing in the previous generation provided the large magnitude of a geometrically initial imperfection of a cylinder (Class III in reference [5]); thus, the values of NASA's previous knockdown factor [4] are relatively lower. However, the modern manufacturing technology nowadays can reduce or minimize a geometrically initial imperfection of a cylinder (Class II or I in the reference [5]) with a wide range of shell thickness ratios (i.e., for thick cylinders to thin cylinders); therefore, the knockdown factor considering a precise modern manufacturing technology may be higher than the previous value. Two recent research projects, NASA's Shell Buckling Knockdown Factor (SBKF) project [5] and the EU's New Robust DESign Guideline for Imperfection Sensitive Composite Launcher Structure (DESICOS) project [6], were conducted to derive newly the knockdown factor using extensive numerical analyses along with bucking tests for the design of lightweight launch vehicle structures. In the SBKF project, metallic orthogrid-stiffened cylinders were considered, and the shell knockdown factors were derived numerically from postbuckling analyses [7-10]. The SBKF project demonstrated that advanced numerical analysis can appropriately determine the knockdown factor of the orthogrid-stiffened cylinder, and the derived shell knockdown factor can provide a light- weight design for space launch vehicle structures [7-10]. In the DESICOS project, composite cylinders without stiffeners were considered to derive the knockdown factor numerically, and the numerical studies [11-16] showed that the derived knockdown factors were higher than NASA's buckling design criteria [4]. In addition to the above works [7-16], extensive postbuckling numerical analyses [17-19] were conducted for various cylinders, such as unstiffened isotropic/composite and orthogrid-stiffened cylinders, and the results obtained were compared with the NASA's previous knockdown factors [4]. Moreover, in-depth nonlinear postbuckling analyses were conducted for the traditional orthogridstiffened and hybrid grid-stiffened cylinders, and the knockdown factors were numerically derived using the calculated global buckling loads without and with geometrically initial imperfection [20]. In the work, the newly derived knockdown factors were higher than the NASA's knockdown factors [4], and the hybrid grid-stiffened cylinder was more efficient than the traditional orthogrid-stiffened cylinder from a buckling design perspective, when the structural weight is considered.

As mentioned previously, a thin-shell structure with an isogrid-stiffened system exhibits an isotropic structural behavior. Thus, the isogrid-stiffened cylinder can be modeled using the equivalent model, without detailed modeling of numerous stiffeners [21-23]. This equivalent model for the isogrid-stiffened structure provides efficient and appropriate precise computations for the overall structural behaviors, such as global buckling. Although isogrid-stiffened cylindrical structures are used extensively in space launch vehicles, limited works are available regarding postbuckling analyses and numerical derivations of shell knockdown factors considering various shell thickness ratios (radius to thickness). However, the knockdown factors of the isogrid-stiffened cylinder considering different shell thickness ratios are required for the buckling design of space launch vehicles with various dimensions (from small to large).

Therefore, this study is aimed at deriving the knockdown factors of isogrid-stiffened cylinders numerically, considering various shell thickness ratios $\left(R / t_{\mathrm{eff}}=536,356,244\right.$, and 122$)$. A detailed model considering numerous stiffeners and an equivalent model without modeling of stiffeners are both used for the finite element modeling of the isogrid-stiffened 


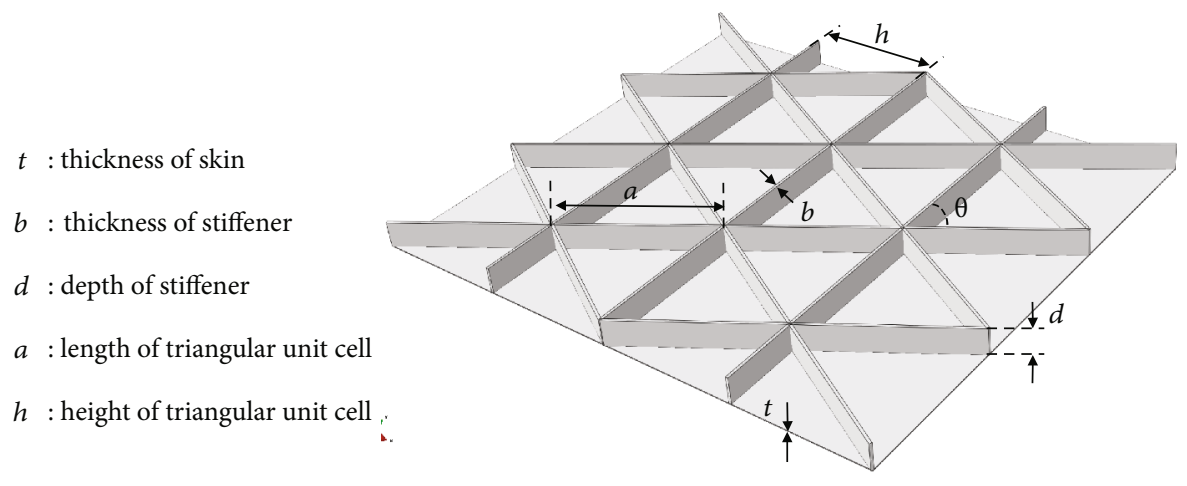

FIgure 3: Schematic diagram of the isogrid-stiffened system.

cylinders. A commercial nonlinear finite element analysis program, ABAQUS (version 6.16), is used for the postbuckling analyses of the isogrid-stiffened cylinders without and with geometrically initial imperfection. The geometrically initial imperfection of the cylinder is modeled using the single perturbation load approach (SPLA), which is considered one of the best methods to represent the most realistic and worst initial imperfections of shell structures [24-27]. In this study, a slightly modified modeling technique for the SPLA $[28,29]$ to the original modeling technique [30] is used. The postbuckling analyses and knockdown factors of the isogrid-stiffened cylinders using the equivalent model are compared to the results with the detailed model for various shell thickness ratios to validate the equivalent modeling techniques. Finally, the knockdown factor function in terms of the shell thickness ratio is expressed using the numerically derived knockdown factors. The derived knockdown factor function for the isogrid-stiffened cylinder is compared to the NASA's knockdown factor function [4] in order to investigate that the present buckling design criteria can provide lighter weight design of space launch vehicles.

\section{Analytical Methods}

2.1. Equivalent Modeling. As the isogrid-stiffened system exhibits the unique characteristics of isotropic behaviors [21], the isogrid-stiffened structure can be modeled as an equivalent and simple model, without detailed modeling of numerous stiffeners. Equations (1)-(6) derive the equivalent elastic modulus $\left(E^{*}\right)$ and equivalent thickness $\left(t^{*}\right)$ of the equivalent cylinder model for the isogrid-stiffened cylinder [21].

The height $(h)$ of a triangular unit cell, as illustrated in Figure 3 for the isogrid-stiffened system, can be defined by Equation (1):

$$
h=\frac{\sqrt{3}}{2} a,
$$

where $a$ is the length of the triangular unit cell and $\alpha$ is defined as

$$
\alpha=\frac{b d}{t h}
$$

in which $b$ and $d$ are the stiffener thickness and depth, respectively. Furthermore, the skin thickness of the isogrid-stiffened cylinder is denoted by $t$. Equation (3) expresses the relation between $d$ and $t$ :

$$
\delta=\frac{d}{t}
$$

Using $\alpha$ and $\delta$, Equation (4) can be defined as

$$
\beta=\sqrt{3 \alpha(1+\delta)^{2}+(1+\alpha)\left(1+\alpha \delta^{2}\right)} .
$$

Finally, the equivalent elastic modulus $\left(E^{*}\right)$ and equivalent thickness $\left(t^{*}\right)$ are calculated using $\alpha$ and $\beta$ as

$$
\begin{aligned}
& E^{*}=E_{0} \frac{(1+\alpha)^{2}}{\beta}, \\
& t^{*}=t \frac{\beta}{1+\alpha},
\end{aligned}
$$

where $E_{0}$ is the elastic modulus of the detailed model. When the equivalent elastic modulus $\left(E^{*}\right)$ and thickness $\left(t^{*}\right)$ are used for modeling, the equivalent model for the isogrid-stiffened cylinder can be obtained without modeling numerous stiffeners. The above procedure for the equivalent modeling is summarized using a flowchart in the Appendix. The equivalent model can effectively save on the computation time and effort of the finite element modeling compared to the detailed model with the modeling of stiffeners.

2.2. Modeling of Isogrid-Stiffened Cylinders with Various Shell Thickness Ratios. For the isogrid-stiffened cylinder, two different thickness can be defined. The first is the equivalent thickness $\left(t^{*}\right)$ in the equivalent modeling as shown in Equation (6). The second is the effective thickness $\left(t_{\text {eff }}\right)$ which can be defined for the grid-stiffened cylinder such as the orthogrid- and isogrid-stiffened cylinders [28]. In the present modeling, the shell thickness ratio (radius to thickness) of the isogrid-stiffened cylinder is defined based on the equivalent thickness $\left(t^{*}\right)$. There are many cases to change the shell thickness ratio $\left(R / t^{*}\right)$ of the isogrid-stiffened cylinder. Therefore, in this work, the radius $(R)$ of the cylinder is changed, but the equivalent thickness of the cylinder $\left(t^{*}\right)$ is maintained as the value of the baseline isogrid-stiffened cylinder model, 
as summarized in Table 1 and Figure 3, to reduce the number of cases for varying the shell thickness ratio.

When the value of $d$ provided in Equation (3) is fixed as the baseline value, the equivalent thickness $\left(t^{*}\right)$ can be also fixed. Moreover, the values of $L / R, a / L$, and $b / h$ are maintained as their baseline values. The modeling procedure for the geometric properties of isogrid-stiffened cylinders with various shell thickness ratios is described as follows. Firstly, the value of $\delta$ is fixed as the baseline value in Table 1 , as expressed in Equation (7):

$$
\delta=\left(\frac{d}{t}\right)_{\text {baseline }} .
$$

Secondly, using the given shell thickness ratio $\left(R / t^{*}\right)_{\text {present }}$ and baseline value of the equivalent thickness $\left(t^{*}\right)$ provided in Table 1 , the radius $\left(R_{\text {present }}\right)$ of the cylinder can be determined as follows:

$$
R_{\text {present }}=t^{*}\left(\frac{R}{t^{*}}\right)_{\text {present }} .
$$

Thirdly, because the slenderness ratio $(L / R)$ has a significant influence on the cylinder buckling characteristics [1719 ], the value of $L / R$ is maintained as the baseline value provided in Table 1 . Therefore, along with the cylinder radius, $R_{\text {present }}$, previously determined in Equation (8), the cylinder length, $L_{\text {present }}$, is designed as

$$
L_{\text {present }}=R_{\text {present }}\left(\frac{L}{R}\right)_{\text {baseline }} .
$$

Fourthly, the length of the triangular unit cell, $a$, in Figure 3 is determined using Equation (10) to maintain the value of $a / L$ as the baseline value, as follows:

$$
a_{\text {present }}=L_{\text {present }}\left(\frac{a}{L}\right)_{\text {baseline }} .
$$

Fifthly, for the given shell thickness ratio $\left(R / t^{*}\right)$, the height of the triangular unit cell (in Figure 3) is obtained using the value previously yielded in Equation (10):

$$
h_{\text {present }}=\frac{\sqrt{3}}{2} a_{\text {present }} \text {, }
$$

where Equation (11) is the same as Equation (1).

Finally, the stiffener thickness for the given shell thickness ratio $\left(R / t^{*}\right)$ can be designed to maintain the baseline value of $b / h$ provided in Table 1 :

$$
b_{\text {present }}=h_{\text {present }}\left(\frac{b}{h}\right)_{\text {baseline }} .
$$

Once the design of the detailed model described above is completed for the given shell thickness ratio $\left(R / t^{*}\right)$, the equivalent elastic modulus $\left(E^{*}\right)$ and thickness $\left(t^{*}\right)$ can be determined using Equations (5) and (6) to obtain the equiv-
Table 1: Properties of the baseline isogrid-stiffened cylinder [31].

\begin{tabular}{lc}
\hline Property & Value \\
\hline Thickness ratio, $R / t_{\text {eff }}\left(R / t^{*}\right)$ & $536(441)$ \\
Radius, $R(\mathrm{~m})$ & 2.250 \\
Length, $L(\mathrm{~m})$ & 2.200 \\
Length of resin ring, $L_{\mathrm{r}}(\mathrm{m})$ & 0.083 \\
Length of a triangular unit cell, $h(\mathrm{~m})$ & 0.360 \\
Height of a triangular unit cell, $a(\mathrm{~m})$ & 0.415 \\
Thickness of stiffener, $b(\mathrm{~m})$ & 0.004 \\
Thickness of skin, $t(\mathrm{~m})$ & 0.004 \\
Effective thickness, $t_{\mathrm{eff}}(\mathrm{m})$ & 0.0042 \\
Equivalent thickness, $t^{*}(\mathrm{~m})$ & 0.0051 \\
Thickness of weld land, $t_{\mathrm{w}}(\mathrm{m})$ & 0.007 \\
Depth of stiffener, $d(\mathrm{~m})$ & 0.008 \\
Angle of stiffener, $\theta$ & $60^{\circ}$ \\
Elastic modulus, $E_{0}(\mathrm{GPa})$ & 73.1 \\
Poisson's ratio, $v$ & 0.33 \\
\hline
\end{tabular}

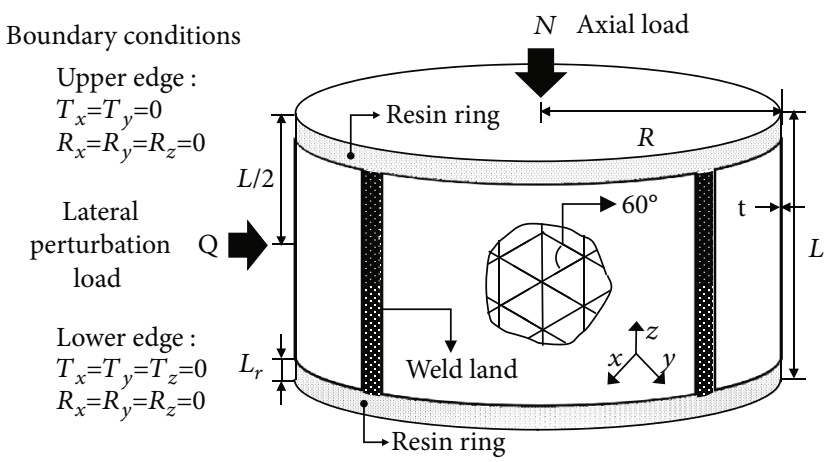

FIgURe 4: Schematic diagram of the isogrid-stiffened cylinder.

alent model for the isogrid-stiffened cylinder. Moreover, the radius and length of the equivalent model are the same as those of the detailed model ( $R_{\text {present }}$ and $L_{\text {present }}$, respectively).

2.3. Isogrid-Stiffened Cylinder Models. The baseline model for the isogrid-stiffened cylinder (with a shell thickness ratio of $\left.R / t_{\text {eff }}=536\right)$ is given in Table 1 and Figure 4 [31]. The material properties (2024 aluminium alloy) are the elastic modulus $\left(E_{0}\right)$ of $73.1 \mathrm{GPa}$ and Poisson's ratio $(v)$ of 0.33 . The cylinder consists of four stiffened panels and unstiffened straps (weld lands) between panels, as indicated in Figure 4. For the boundary conditions of a cylinder, all degrees of freedom at the bottom edge are constrained, but all degrees of freedoms except for the translational one in the $z$-direction are constrained at the top edge, as illustrated in Figure 4. It is worth noting that the equivalent modeling technique is applied only to the grid-stiffened panels and not to the weld lands. Thus, the weld land thickness $\left(t_{\mathrm{w}}\right)$ in the equivalent model is equal to that in the detailed model. The properties of the isogrid-stiffened cylinders when using the detailed and equivalent models considering various shell thickness ratios, as described in the previous section, are summarized in Tables 2 and 3, respectively. 
TABLE 2: Properties of the detailed models for the isogrid-stiffened cylinders with various shell thickness ratios.

\begin{tabular}{|c|c|c|c|c|}
\hline Thickness ratio, $R / t_{\text {eff }}\left(R / t^{*}\right)$ & $536(441)$ & $356(300)$ & $244(200)$ & $122(100)$ \\
\hline Radius, $R(\mathrm{~m})$ & 2.250 & 1.530 & 1.020 & 0.510 \\
\hline Length, $L(\mathrm{~m})$ & 2.200 & 1.500 & 1.000 & 0.500 \\
\hline Length of resin ring, $L_{\mathrm{r}}(\mathrm{m})$ & 0.083 & 0.056 & 0.035 & 0.019 \\
\hline Length of a triangular unit cell, $h(\mathrm{~m})$ & 0.360 & 0.282 & 0.188 & 0.094 \\
\hline Height of a triangular unit cell, $a(\mathrm{~m})$ & 0.415 & 0.244 & 0.163 & 0.082 \\
\hline Thickness of stiffener, $b(\mathrm{~m})$ & 0.004 & 0.0027 & 0.0018 & 0.0009 \\
\hline Thickness of skin, $t(\mathrm{~m})$ & \multicolumn{4}{|c|}{0.004} \\
\hline Effective thickness, $t_{\text {eff }}(\mathrm{m})$ & \multicolumn{4}{|c|}{0.0042} \\
\hline Thickness of weld land, $t_{\mathrm{w}}(\mathrm{m})$ & \multicolumn{4}{|c|}{0.007} \\
\hline Depth of stiffener, $d(\mathrm{~m})$ & \multicolumn{4}{|c|}{0.008} \\
\hline Angle of stiffener, $\theta$ & \multicolumn{4}{|c|}{$60^{\circ}$} \\
\hline Elastic modulus, $E_{0}(\mathrm{GPa})$ & \multicolumn{4}{|c|}{73.1} \\
\hline Poisson's ratio, $v$ & \multicolumn{4}{|c|}{0.33} \\
\hline
\end{tabular}

TABle 3: Properties of the equivalent models for the isogridstiffened cylinders with various shell thickness ratios.

\begin{tabular}{lcccc}
\hline Thickness ratio, $R / t_{\text {eff }}\left(R / t^{*}\right)$ & 536 & 356 & 244 & 122 \\
& $(441)$ & $(300)$ & $(200)$ & $(100)$ \\
\hline Radius, $R(\mathrm{~m})$ & 2.250 & 1.530 & 1.020 & 0.510 \\
Length, $L(\mathrm{~m})$ & 2.200 & 1.500 & 1.000 & 0.500 \\
Length of resin ring, $L_{\mathrm{r}}(\mathrm{m})$ & 0.083 & 0.056 & 0.035 & 0.019 \\
Thickness of weld land, $t_{\mathrm{w}}$ & & 0.007 & \\
$(\mathrm{~m})$ & & 0.0051 & \\
Equivalent thickness, $t^{*}(\mathrm{~m})$ & & 58.35 & \\
Equivalent elastic modulus, & & & \\
$E^{*}(\mathrm{GPa})$ & & 0.33 & \\
Poisson's ratio, $v$ & & & \\
\hline
\end{tabular}

2.4. Finite Element Modeling and Analysis Techniques for Isogrid-Stiffened Cylinders. The nonlinear finite element analysis program, ABAQUS, is used for the postbuckling analyses of the isogrid-stiffened cylinders under axial compressive loads in this work. For the detailed modeling (Figure 5(a)), the skin structures for the grid-stiffened region are modeled using three-node shell elements, while the stiffener and weld lands are modeled with four-node shell elements; however, only four-node shell elements are used for the equivalent modeling of the isogrid-stiffened cylinder (Figure 5(b)). Table 4 shows the number of finite elements used for the modeling of the isogrid-stiffened cylinders considering various shell thickness ratios. As indicated in the table, the equivalent model uses substantially fewer finite elements for the modeling than the detailed model, since the equivalent model does not model the stiffeners, and represents the isogrid-stiffened cylinder as a simple cylinder without stiffeners.

2.5. Analysis Techniques. The SPLA is considered the best method for representing the geometrically initial imperfection of thin-shell structures, as it can represent the realistic and worst geometric imperfection of cylindrical structures

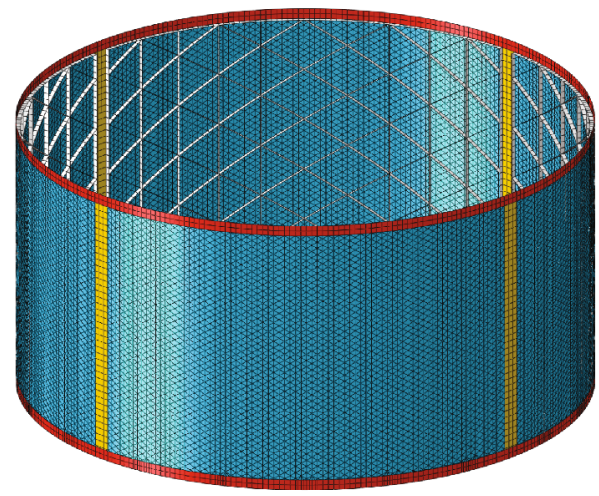

(a) Detailed model

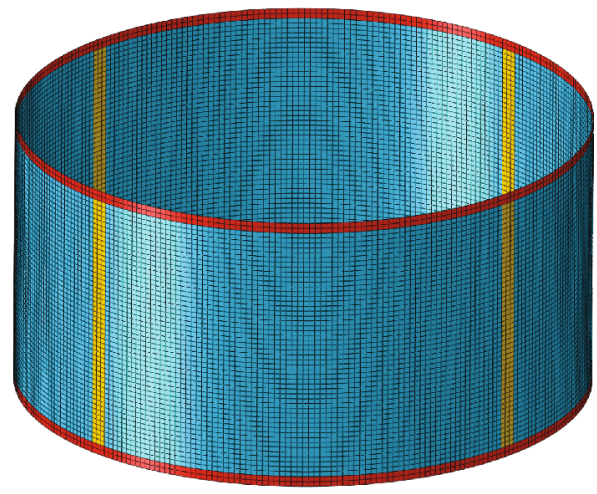

(b) Equivalent model

FIgURE 5: ABAQUS finite element models for the isogrid-stiffened cylinder.

TABLE 4: Number of finite elements of the isogrid-stiffened cylinders with various shell thickness ratios.

\begin{tabular}{lcccc}
\hline $\begin{array}{l}\text { Thickness ratio, } \\
R / t_{\text {eff }}\left(R / t^{*}\right)\end{array}$ & $536(441)$ & $356(300)$ & $244(200)$ & $122(100)$ \\
\hline Detailed model & 33,128 & 33,128 & 33,228 & 33,288 \\
Equivalent model & 17,064 & 15,768 & 13,608 & 6,656 \\
\hline
\end{tabular}




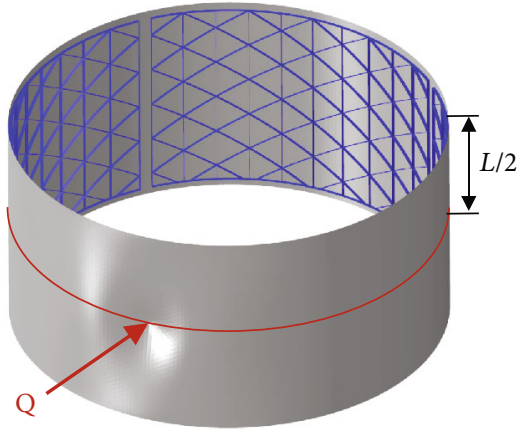

(a) Lateral perturbation load

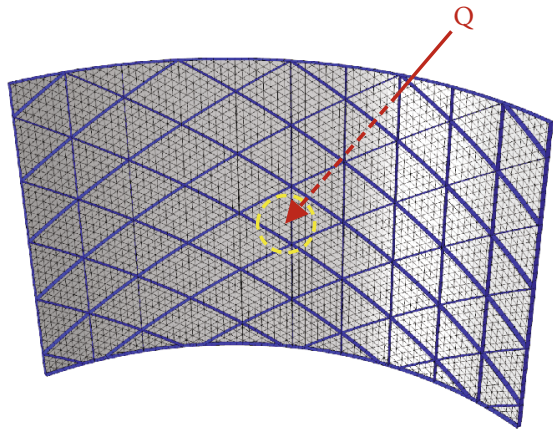

(b) Application point of a lateral load

FIGURE 6: Single perturbation load approach (SPLA).

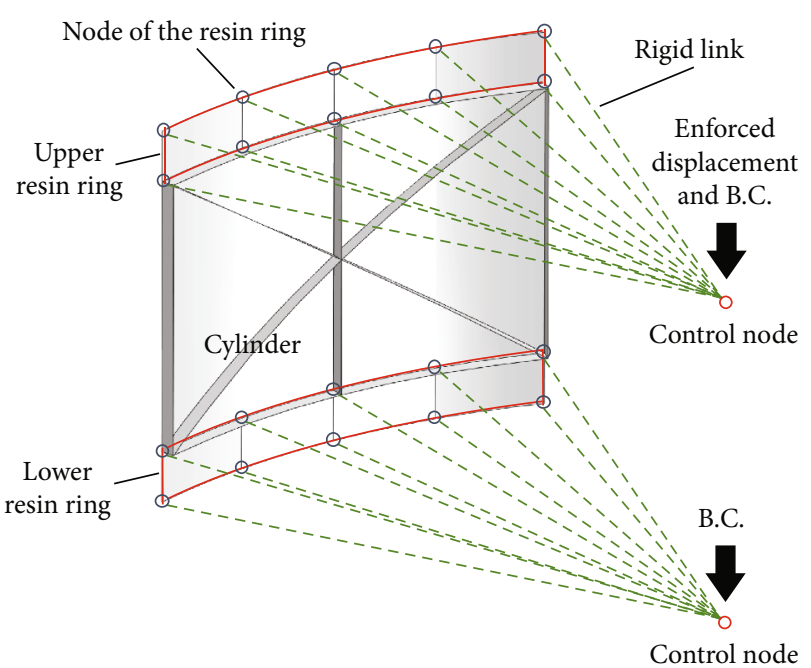

FIgURE 7: Rigid rinks and control nodes.

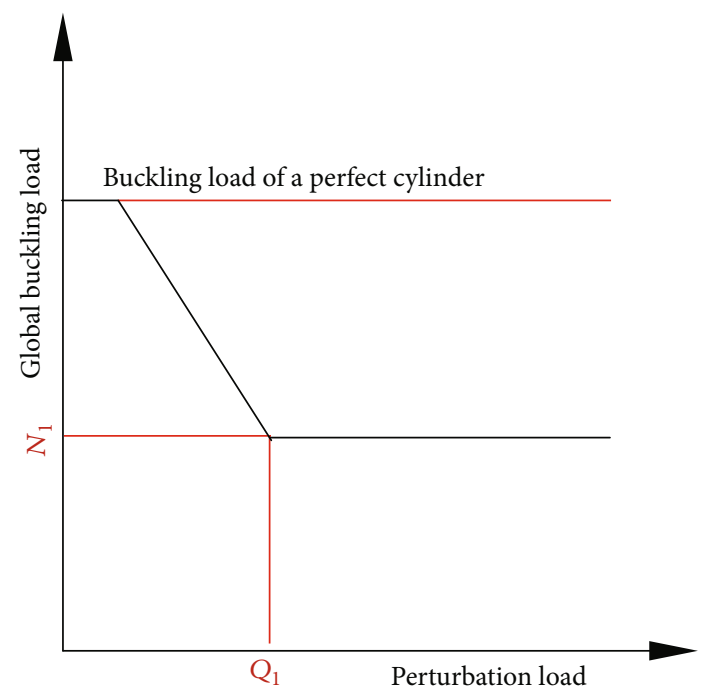

Figure 8: Global buckling load in terms of a perturbation load.

[24-27]. Therefore, the SPLA is used to represent the geometrically initial imperfection of both the detailed and equivalent models for the isogrid-stiffened cylinders. The SPLA is

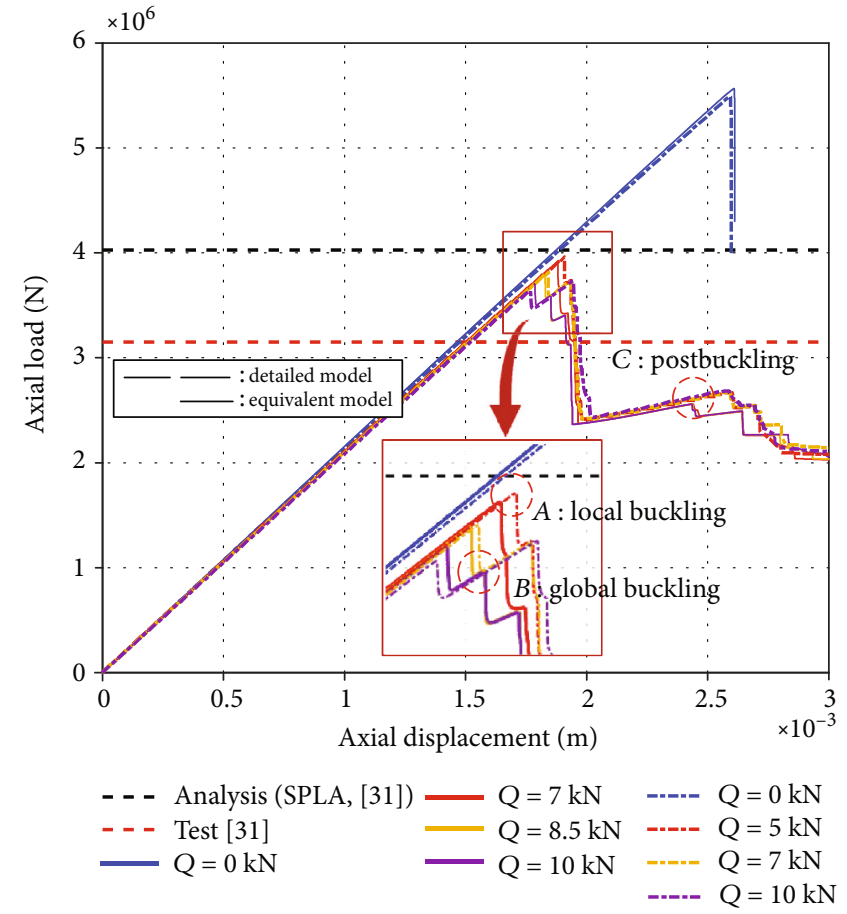

FIgURE 9: Postbuckling analysis results of the isogrid-stiffened cylinder (baseline model, $R / t_{\text {eff }}=536$ ).

represented using the following three-step process [28, 29], which differs slightly from the original modeling [30].

Firstly, an assumed perturbation load $(Q)$ in the radial direction is applied to the middle of the cylinder (Figure 6(a), [24-30]). In the present work, for the detailed model of the isogrid-stiffened cylinder, the radial perturbation load is applied to the intersection point between the axial stiffener of a grid panel and the cylinder's middle line, as shown in Figure 6(b); however, the application point of the radial perturbation load for the equivalent model is considered to be the same point as in the detailed model. Nonlinear static analysis using ABAQUS is conducted for the isogridstiffened cylinder under the prescribed radial perturbation load in this step.

Secondly, the deformed configuration of the cylinder obtained from the previous step is imposed to the perfect 


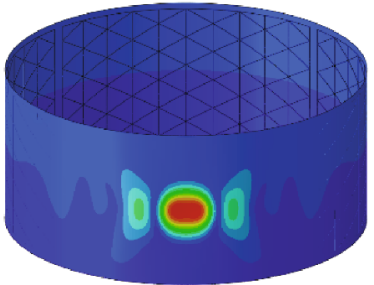

A. Local buckling

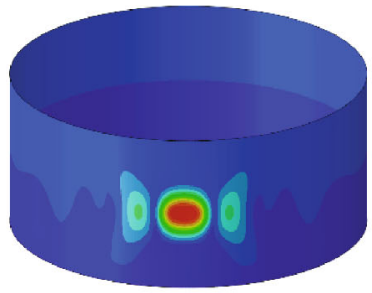

A. Local buckling

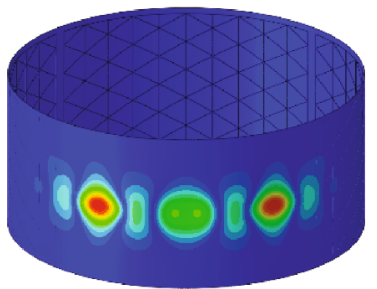

B. Global buckling

(a) Detailed model $(Q=8.5 \mathrm{kN})$

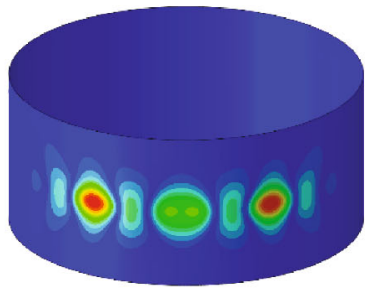

B. Global buckling

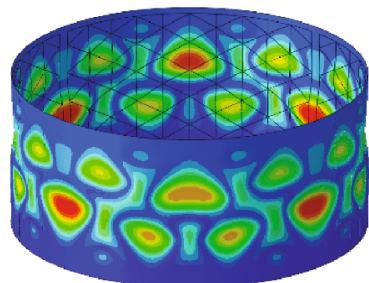

C. Postbuckling

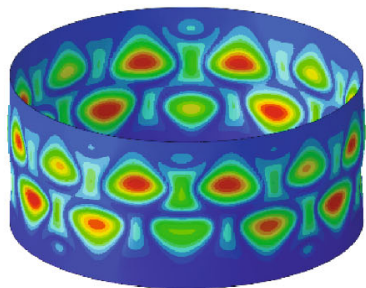

C. Postbuckling

(b) Equivalent model $(Q=7 \mathrm{kN})$

Figure 10: Deformed shapes of the isogrid-stiffened cylinder $\left(R / t_{\text {eff }}=536\right)$.

cylinder by modifying the nodal coordinates of the cylinder's finite element model $[28,29]$. This modeling can represent a cylinder with geometrically initial imperfection in a stress-free state, which provides realistic modeling of the initial imperfections of thin-shell structures [24-27].

Finally, using the method given in the previous works $[28,29]$, axial displacement instead of axial compressive force is applied to the edges of the isogrid-stiffened cylinder considering the geometrically initial imperfection for the postbuckling analysis, since the Newton-Raphson method along with the displacement control method is applied for the postbuckling analysis in this work. Moreover, all of the nodes at the resin ring region of the cylinder are coupled with a control node using rigid links (Figure 7) to achieve a uniform displacement condition. Axial displacement instead of axial force is applied to the control node to provide the displacement control method. Artificial damping with a value of 5\% is used to stabilize the nonlinear analysis with local instabilities such as snap through, local buckling, and wrinkling, because it dissipates the released strain energy when local instability occurs [32]. In this step, the relationship between the axial force and displacement of the cylinder under axial compressive forces is obtained, along with the predicted global and local buckling loads.

The above process with three steps is repeated as the single perturbation load $(Q)$ is increased, until the global buckling load converges. As illustrated in Figure 8, as the radial perturbation load increases, the global buckling load of the cylinder with geometrically initial imperfection decreases compared to that of the perfect cylinder without initial imperfection. In the SPLA, when the perturbation load exceeds a certain perturbation load $\left(Q_{1}\right.$ in Figure 8$)$, the global buckling load of the cylinder with initial imperfection does not decrease but remains almost constant, although the single perturbation load increases further. The corresponding global buckling load is also defined as the design load $\left(N_{1}\right)$ of the cylinder for the postbuckling analysis. Using the calculated global buckling loads without and with initial imperfection, the buckling knockdown factor (or shell knockdown factor), $\gamma$, is derived as follows:

$$
\gamma=\frac{\left(N_{\mathrm{cr}}\right)_{\text {imperfect }}}{\left(N_{\mathrm{cr}}\right)_{\text {prefect }}},
$$

where $\left(N_{\mathrm{cr}}\right)_{\text {perfect }}$ and $\left(N_{\mathrm{cr}}\right)_{\text {imperfect }}$ are the global buckling loads of the cylinder without and with initial imperfection, respectively. Although the present nonlinear analysis may observe the local buckling as well as the global buckling of a cylinder, the knockdown factor is defined using the global buckling loads without and with initial imperfection, as shown in Equation (13).

\section{Numerical Results}

3.1. Shell Thickness Ratio of $R / t_{\text {eff }}=536$ (Baseline Model). Prior to the postbuckling analyses and derivation of the shell knockdown factors of the isogrid-stiffened cylinders considering various shell thickness ratios, postbuckling analyses using both the detailed and equivalent models are conducted for the baseline model $\left(R / t_{\text {eff }}=536\right.$, [31]). In this section, the shell knockdown factors are derived using the calculated global buckling loads. Figure 9 presents the postbuckling analyses for the baseline isogrid-stiffened cylinder model. For the perfect cylinder without initial imperfection, the detailed and equivalent models predict global buckling loads of 5,560 and $5,490 \mathrm{kN}$, respectively. As the perturbation load (Q) increases, the global buckling loads converge for both the detailed and equivalent models. When the initial imperfection is considered, the global buckling loads $(B)$ are 
TABLE 5: Postbuckling analysis results of the isogrid-stiffened cylinders with various shell thickness ratios $\left(R / t_{\text {eff }}=536,356,244\right.$, and 122$)$.

\begin{tabular}{|c|c|c|c|c|}
\hline Thickness ratio, $R / t_{\mathrm{eff}}\left(R / t^{*}\right)$ & $536(441)$ & $356(300)$ & $244(200)$ & $122(100)$ \\
\hline \multicolumn{5}{|c|}{ Global buckling load without initial imperfection, $\left(N_{\mathrm{cr}}\right)_{\text {perfect }}$} \\
\hline Detailed model $(\mathrm{kN})$ & 5,560 & 5,400 & 5,460 & 5,630 \\
\hline Equivalent model $(\mathrm{kN})$ & 5,490 & 5,450 & 5,570 & 5,750 \\
\hline Relative error (\%) & -1.26 & 0.93 & 2.01 & 2.13 \\
\hline \multicolumn{5}{|c|}{ Global buckling load with initial imperfection, $\left(N_{\mathrm{cr}}\right)_{\text {imperfect }}$} \\
\hline Detailed model (kN) & 3,600 & 3,900 & 4,330 & 4,480 \\
\hline Equivalent model $(\mathrm{kN})$ & 3,730 & 3,990 & 4,430 & 4,500 \\
\hline Relative error (\%) & 3.61 & 2.31 & 2.31 & 0.45 \\
\hline \multicolumn{5}{|l|}{ Knockdown factor, $\gamma$} \\
\hline NASA SP-8007 [4] & 0.31 & 0.38 & 0.44 & 0.47 \\
\hline Detailed model & 0.647 & 0.722 & 0.793 & 0.796 \\
\hline Equivalent model & 0.679 & 0.732 & 0.795 & 0.783 \\
\hline Relative error (\%) & 4.93 & 1.37 & 0.29 & -1.65 \\
\hline \multicolumn{5}{|l|}{ Computation time } \\
\hline Detailed model (min.) & 64 & 67 & 46 & 40 \\
\hline Equivalent model (min.) & 38 & 27 & 26 & 25 \\
\hline Equivalent model/detailed model (\%) & 59.4 & 40.3 & 56.5 & 62.5 \\
\hline
\end{tabular}

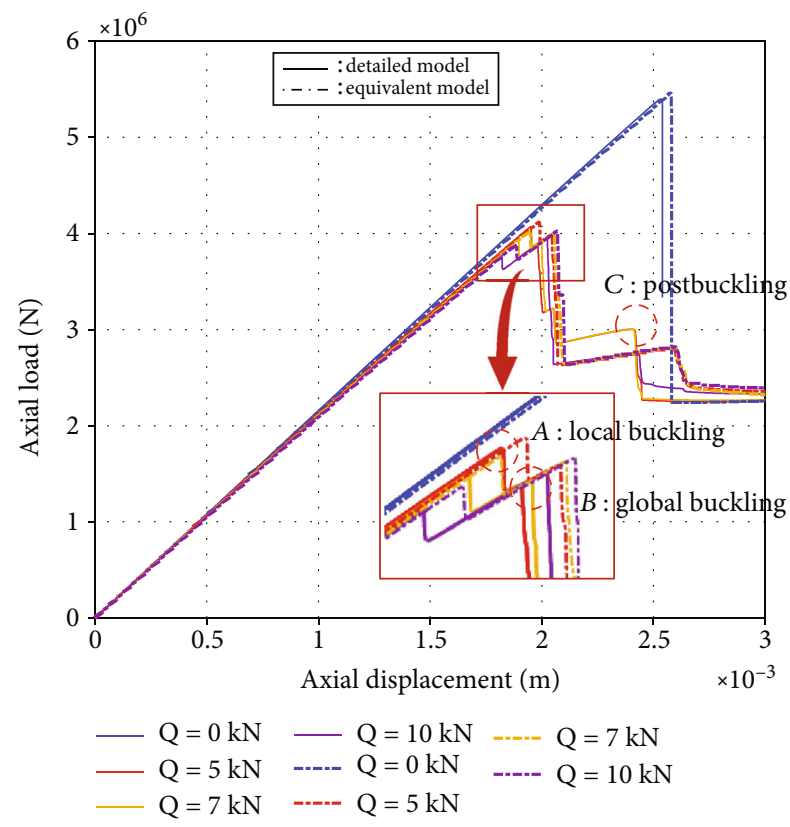

FIGURE 11: Postbuckling analysis results of the isogrid-stiffened cylinder $\left(R / t_{\text {eff }}=356\right)$.

calculated as 3,600 and $3,730 \mathrm{kN}$ by the detailed and equivalent models, respectively. As indicated in the figure, the global buckling loads using the detailed and equivalent models are very close for both the results without and with initial imperfection, as the relative errors are -1.26 and $3.61 \%$, respectively. Figure 10 compares the deformed shapes of the baseline cylinder using the detailed and equivalent models. It can be observed that the two models provide rather similar deformed configurations of the baseline cylinder in the local buckling $(A)$, global buckling $(B)$, and post- buckling $(C)$ states. Using the calculated global buckling loads of the baseline model without and with initial imperfection, the buckling knockdown factors are derived as 0.647 and 0.679 for the detailed and equivalent models, respectively, and compare well to each other. The results of the postbuckling analysis and derivation of the knockdown factor for the baseline model are summarized in Table 5. As indicated in Figures 9 and 10, as well as in Table 5, the equivalent model for the isogrid-stiffened cylinder provides reasonably accurate predictions for the global buckling loads without and with initial imperfection and the knockdown factors, despite using $59 \%$ of the computation time of the postbuckling analysis using the detailed model. The relative error for the global buckling load in the previous work [28] is very significant $(27.8 \%)$ between the analysis using SPLA $(4,027 \mathrm{kN})$ and the measured data in the buckling test $(3,151 \mathrm{kN})$. However, the relative errors between the present buckling loads using the detailed and equivalent models to the test data are 14.25 and $18.38 \%$, respectively. Thus, the prediction in this work is more accurate than the previous work [31]. The knockdown factor using the test data is given as 0.616 and the knockdown factor with SPLA is derived as 0.787 in the previous study [31]; however, the present detailed and equivalent models derive the knockdown factors of 0.647 and 0.679 , respectively. Since the relative errors of knockdown factors using the detailed and equivalent models in this work are 5.03 and $10.23 \%$ to the value with the test data, respectively, it is believed that the derivation technique of the knockdown factor is appropriately established using the detailed and equivalent models for the isogrid-stiffened cylinder.

3.2. Shell Thickness Ratio of $R / t_{\text {eff }}=356$. Using the modeling technique described in Section 2.2, the shell thickness ratio of the isogrid-stiffened cylinder is changed from the baseline 


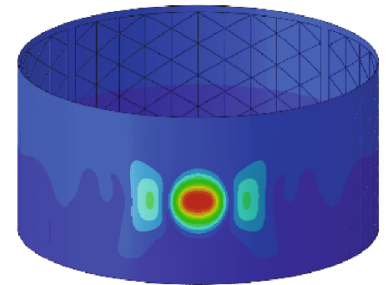

A. Local buckling

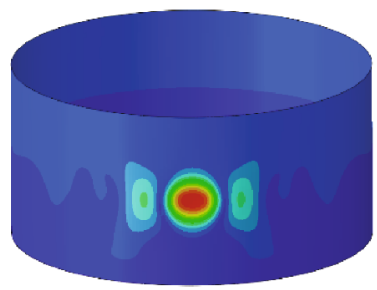

A. Local buckling

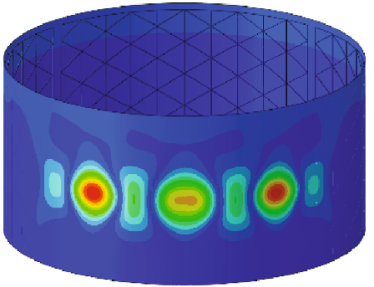

B. Global buckling

(a) Detailed model $(Q=5 \mathrm{kN})$

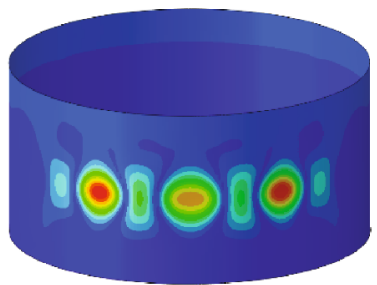

B. Global buckling

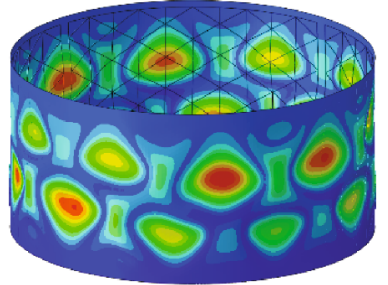

C. Postbuckling

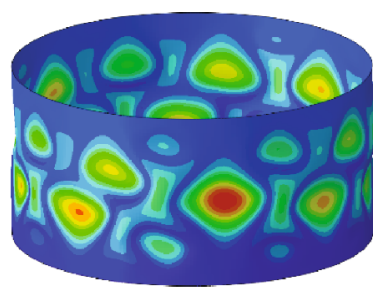

C. Postbuckling

(b) Equivalent model $(Q=5 \mathrm{kN})$

Figure 12: Deformed shapes of the isogrid-stiffened cylinder $\left(R / t_{\mathrm{eff}}=356\right)$.

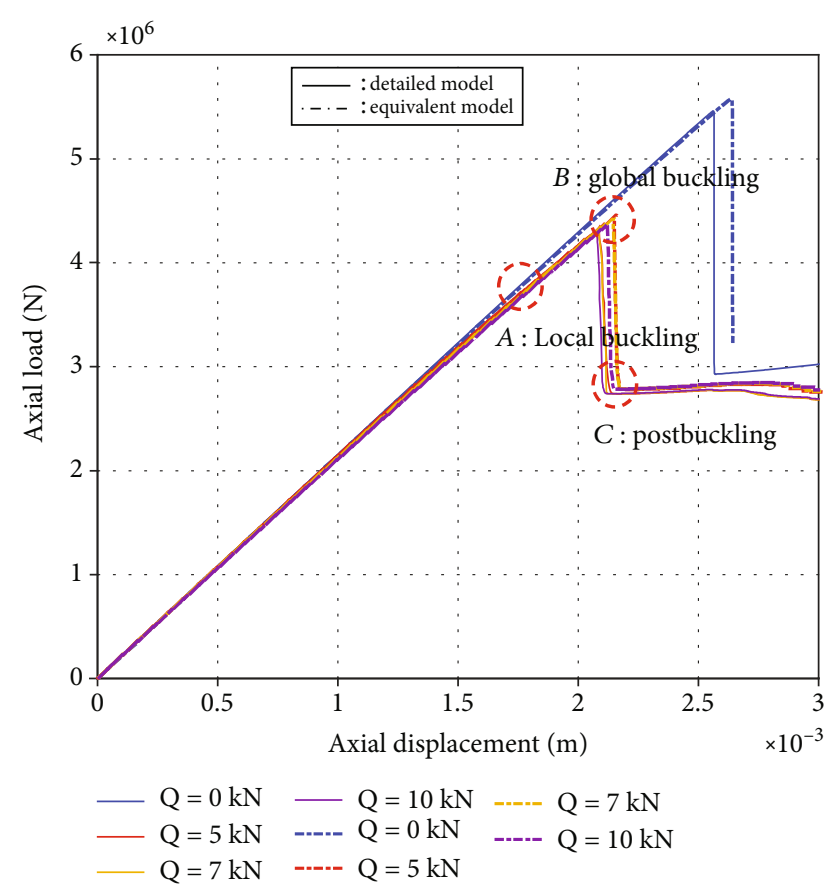

FIGURE 13: Postbuckling analysis results of the isogrid-stiffened cylinder $\left(R / t_{\text {eff }}=244\right)$.

value, while its slenderness ratio $(L / R)$ is maintained. The postbuckling analysis results for the isogrid-stiffened cylinder with a shell thickness ratio $\left(R / t_{\text {eff }}\right)$ of 356 using the detailed and equivalent models are presented in Figure 11. For the perfect cylinder without initial imperfection, the global buckling loads are calculated as 5,400 and 5,450 kN when using the detailed and equivalent models, respectively. These values are higher than the results of the previous baseline case with $R / t_{\text {eff }}=536$. When the geometrically initial imperfection is considered, the global buckling loads $(B)$ of the isogridstiffened cylinder are converged to 3,900 and 3,990 kN when using the detailed and equivalent models, respectively. These global buckling loads are also higher than the values of the baseline model considering the initial imperfection. The knockdown factors are derived as 0.722 and 0.732 for the detailed and equivalent models, respectively, using Equation (13), as indicated in Table 5. These knockdown factors with $R / t_{\text {eff }}=356$ are higher than the results obtained when using the baseline model. As summarized in Table 5, the global buckling load and knockdown factor predicted using the equivalent model compare well with those using the detailed model, although the computation time with the equivalent model is approximately $40 \%$ of that using the detailed model. The deformed shapes of the isogrid-stiffened cylinder in the local buckling, global buckling, and postbuckling states are plotted in Figure 12. As indicated in the figure, the two models give similar deformed configurations in the local buckling $(A)$ and global buckling $(B)$ states; however, the postbuckling shapes $(C)$ of the cylinder using the detailed and equivalent models are moderately different from each other.

3.3. Shell Thickness Ratio of $R / t_{\text {eff }}=244$. Figure 13 illustrates the relationship between the axial load and axial displacement in the postbuckling analyses for the isogrid-stiffened cylinder with a shell thickness ratio of 244 . The global buckling loads are predicted as 5,460 and $5,570 \mathrm{kN}$, respectively, when the geometrically initial imperfection is not considered for the detailed and equivalent models. The two results are quite similar, with a relative error of $2.01 \%$. The converged global buckling loads using the detailed and equivalent models are 4,330 and 4,430 kN, respectively, when the geometrically initial imperfection is considered. These loads are higher than the results obtained in the previous case with $R$ $/ t_{\text {eff }}=356$, and the relative error between the two results using the detailed and equivalent models is $2.31 \%$, as given 


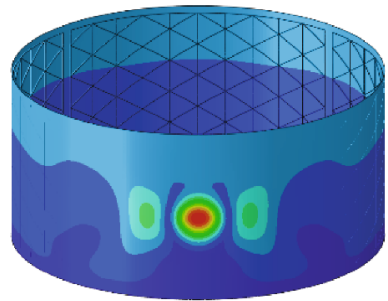

A. Local buckling

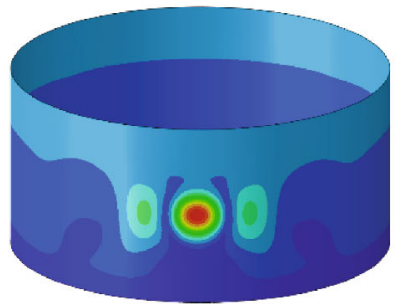

A. Local buckling

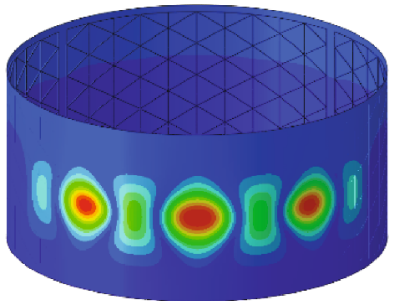

B. Global buckling

(a) Detailed model $(Q=5 \mathrm{kN})$

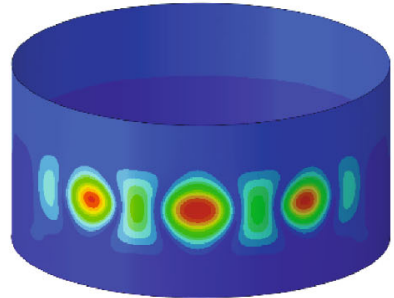

B. Global buckling

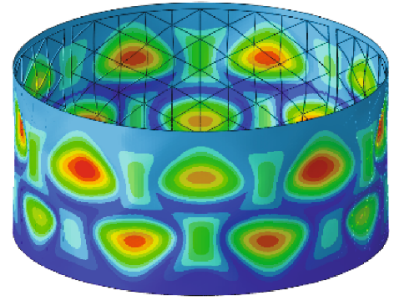

C. Postbuckling

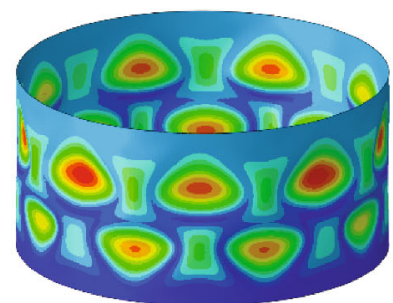

C. Postbuckling

(b) Equivalent model $(Q=5 \mathrm{kN})$

Figure 14: Deformed shapes of the isogrid-stiffened cylinder $\left(R / t_{\text {eff }}=244\right)$.

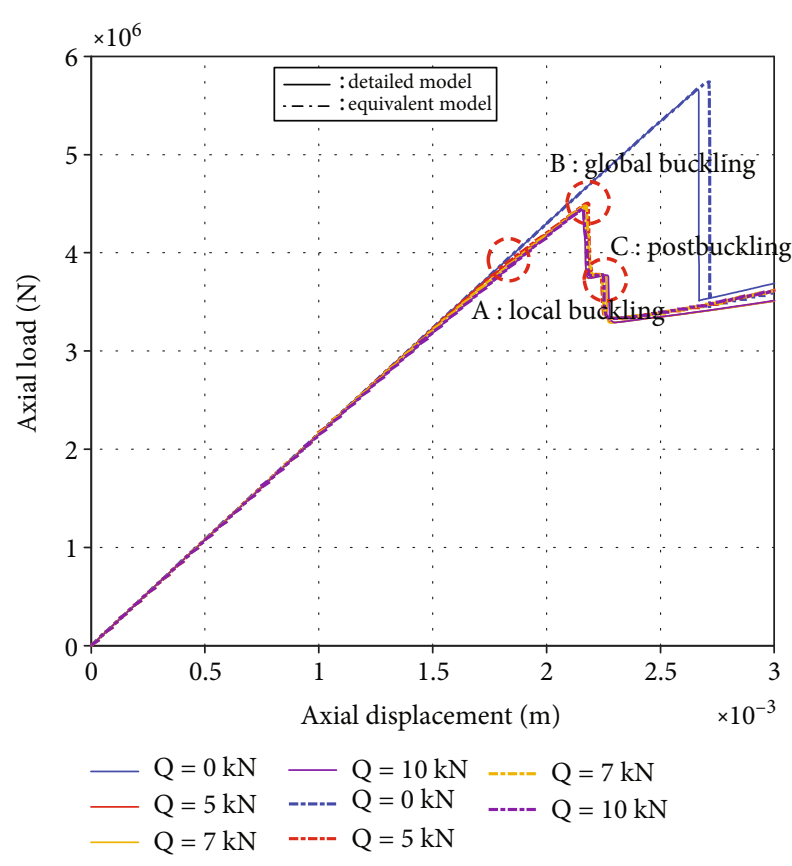

Figure 15: Postbuckling analysis results of the isogrid-stiffened cylinder $\left(R / t_{\text {eff }}=122\right)$.

in Table 5. The knockdown factors for the isogrid-stiffened cylinder with $R / t_{\text {eff }}=244$ are derived as 0.793 and 0.795 for the detailed and equivalent models, respectively, as indicated in Table 5; thus, the relative error between the two results is very small $(0.29 \%)$. These knockdown factors are higher than those obtained with $R / t_{\text {eff }}=356$. Similarly, to the previous example, the computation time when using the equivalent model is approximately $57 \%$ of that when using the detailed model. Figure 14 illustrates the deformed shapes of the isogrid-stiffened cylinder with a shell thickness ratio of 244 .
As indicated in the figure, the deformed configurations of the cylinder in the local buckling $(A)$, global buckling $(B)$, and postbuckling $(C)$ states predicted by the equivalent model are quite similar to those using the detailed model.

3.4. Shell Thickness Ratio of $R / t_{\text {eff }}=122$. Figure 15 shows the postbuckling analyses when using the detailed and equivalent models for the isogrid-stiffened cylinder with a shell thickness ratio of 122 . For the perfect cylinder without initial imperfection, the global buckling loads are calculated as 5,630 and $5,750 \mathrm{kN}$ when using the detailed and equivalent models, respectively. For the cylinder considering the initial imperfection, the global buckling loads predicted by the detailed and equivalent models are both converged well as the perturbation load increases. The detailed and equivalent models predict the global buckling loads $(B)$ as 4,480 and $4,500 \mathrm{kN}$, respectively, for the isogrid-stiffened cylinder with initial imperfection. The relative errors for the cylinder without and with the initial imperfection are determined as $2.13 \%$ and $0.45 \%$, respectively, as summarized in Table 5. Moreover, the global buckling loads of the isogrid-stiffened cylinder with $R / t_{\text {eff }}=122$ are higher than those with $R / t_{\text {eff }}=244$ in the previous example. Using the calculated global buckling loads without and with the initial imperfection, the knockdown factors are derived as 0.796 and 0.783 for the detailed and equivalent models, respectively. As in the previous case, the derived knockdown factors using the two models are similar to each other, and they are higher than the knockdown factors with $R / t_{\text {eff }}=244$. As shown in Table 5 , the calculation time when using the equivalent model is approximately $63 \%$ of that when using the detailed model, although the global buckling load and knockdown factor predicted using the equivalent model compare well with those using the detailed model. The deformed shapes of the isogrid-stiffened cylinder with $R / t_{\text {eff }}=122$ are plotted in Figure 16 . The detailed and 


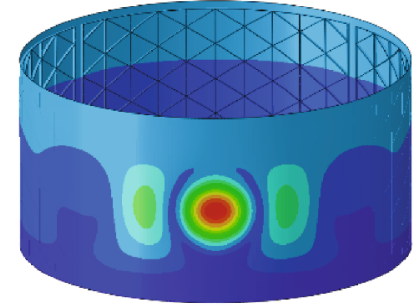

A. Local buckling

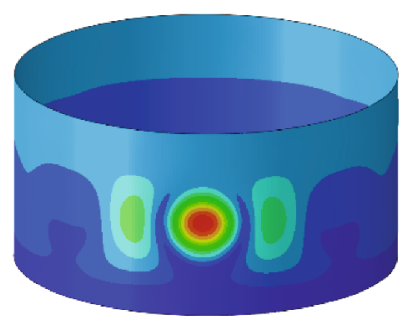

A. Local buckling

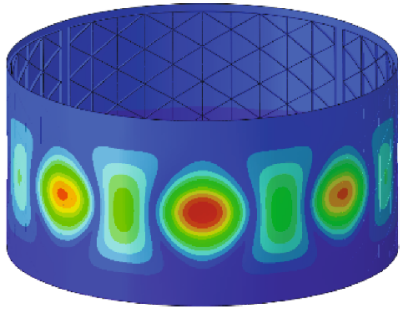

B. Global buckling

(a) Detailed model $(Q=5 \mathrm{kN})$

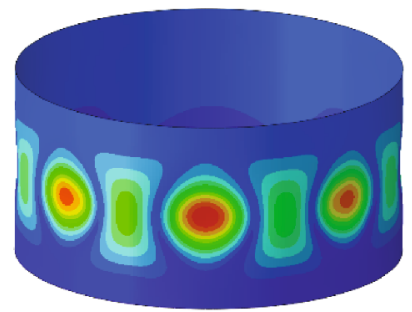

B. Global buckling

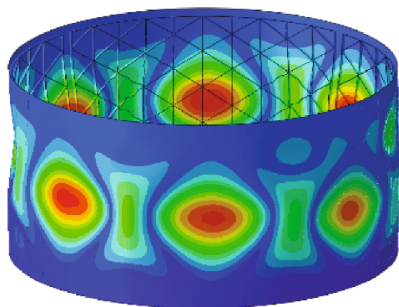

C. Postbuckling

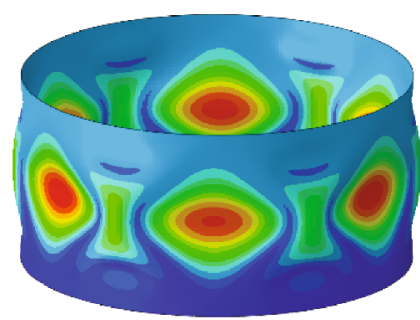

C. Postbuckling

(b) Equivalent model $(Q=5 \mathrm{kN})$

Figure 16: Deformed shapes of the isogrid-stiffened cylinder $\left(R / t_{\mathrm{eff}}=122\right)$.

equivalent models exhibit similar deformed configurations in the local buckling $(A)$, global buckling $(B)$, and postbuckling (C) states.

\subsection{Knockdown Factor Function in terms of Shell Thickness} Ratio. The knockdown factor should be expressed in terms of the shell thickness ratio for the structural design of isogrid-stiffened cylinders considering various dimensions. As similar to NASA's knockdown factor function [4], expressed by Equation (14), the knockdown factor function for the isogrid-stiffened cylinder is derived using the knockdown factors calculated in the previous sections. Using curve fitting, the knockdown factor function in this work is derived based on the form of the NASA's knockdown factor function shown in Equation (14). The curve-fitting tool with the exponential model in MATLAB [33] is used for the curve fitting. Equations (15) and (16) represent the knockdown factor functions for the isogrid-stiffened cylinder using the detailed and equivalent models, respectively. Figure 17 compares the knockdown factor functions (Equations (15) and (16)) for the isogrid-stiffened cylinder derived in this work with NASA's knockdown factor function (Equation (14)). It can be observed that the calculated knockdown factors using the detailed and equivalent models are quite similar to each other when the shell thickness ratios are 536, 356, 244, and 122. Moreover, the knockdown factor values derived using the detailed and equivalent models both compare excellently with the value given in Ref. [31] when the shell thickness ratio is 536. Thus, the knockdown factors derived using the two models are successfully validated. The knockdown factor functions using the detailed and equivalent models (Equations (15) and (16), respectively) are nearly identical when the shell thickness ratio is up to 600 . Although the values of the shell thickness ratio for actual propellant tank structures are not available in the public domain, it is believed that the

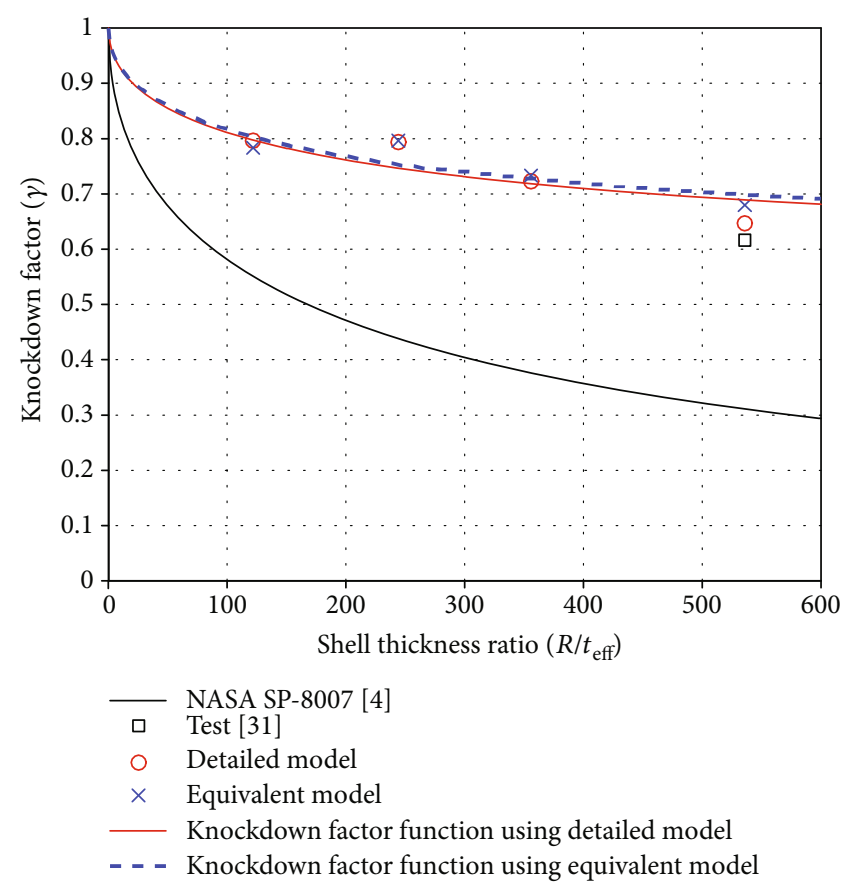

FIGURE 17: Knockdown factor functions for the isogrid-stiffened cylinder in terms of the shell thickness ratio.

range of the present shell thickness ratio given in Figure 17 is reasonable since the previous work [5] considered the shell thickness ratio of 50 to 350 for the full-scale structural models. Furthermore, the knockdown factor functions are substantially higher than NASA's knockdown factor function. Therefore, the buckling design of isogrid-stiffened cylinders using the presented knockdown factor function can facilitate in developing lightweight launch vehicle structures 


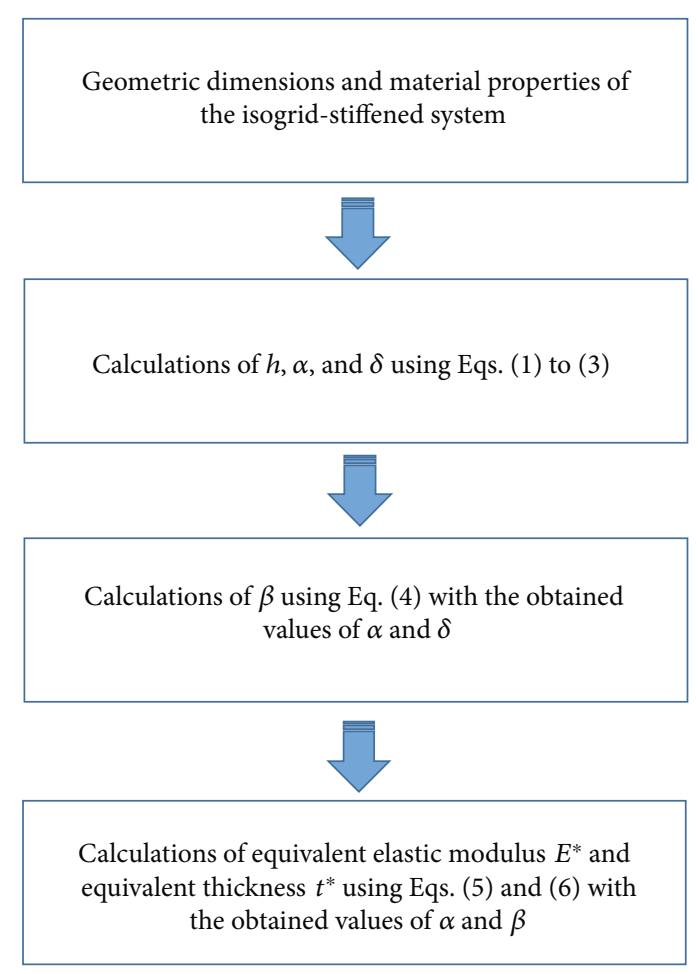

FIGURE 18: Flowchart for the equivalent modeling of an isogridstiffened system.

compared to the design using the previous buckling design criteria [4].

$$
\begin{aligned}
& \gamma=1-0.901\left(1-e^{-1 / 16 \sqrt{R / t_{\text {eff }}}}\right), \\
& \gamma=1-0.407\left(1-e^{-1 / 16 \sqrt{R / t_{\text {eff }}}}\right), \\
& \gamma=1-0.395\left(1-e^{-1 / 16 \sqrt{R / t_{\text {eff }}}}\right) .
\end{aligned}
$$

\section{Conclusions}

In this study, the buckling knockdown factors of isogridstiffened cylinders under axial compressive loads were derived considering various shell thickness ratios. Isogridstiffened cylinders with shell thickness ratios of 536, 356, 244, and 122 were used. A detailed model considering modeling of numerous stiffeners and an equivalent model without modeling of stiffeners were used for the finite element modeling of the isogrid-stiffened cylinders. Postbuckling analyses using ABAQUS were conducted for the isogridstiffened cylinders represented by the detailed and equivalent models to derive the knockdown factors. The geometrically initial imperfection of the cylinder was modeled using the SPLA, and Newton-Raphson method with the displacement control method was applied for the nonlinear static postbuckling analyses. The global buckling loads obtained using the equivalent model were quite similar to those of the detailed model for all of the shell thickness ratios considered, as the relative errors were within $5 \%$ for the cylinders without and with initial imperfection. Moreover, the derived knockdown factors when using the equivalent model were compared excellently with the values obtained when using the detailed model, with relative errors of less than $5 \%$. In addition to the accurate prediction capability offered by the equivalent model for isogrid-stiffened cylinders, because the computation time when using the equivalent model was $40 \%$ to $63 \%$ of that when using the detailed model, it was shown that the equivalent modeling technique was highly efficient for the modeling and postbuckling analysis of the isogrid-stiffened cylinders under compressive axial forces. Using the calculated knockdown factors, the knockdown factor functions for the isogrid-stiffened cylinders were expressed in terms of the shell thickness ratio. The knockdown factor functions using the detailed and equivalent models were quite similar to each other. Furthermore, the derived knockdown factor function for the isogrid-stiffened cylinder was significantly higher than NASA's knockdown factor function when a shell thickness ratio of up to 600 was considered. Therefore, it can be concluded that the presented knockdown factor function can facilitate the development of lightweight launch vehicle structures using isogrid-stiffened cylinders.

\section{Appendix}

\section{A. The Equivalent Modeling Process of an Isogrid-Stiffened Cylinder}

The flowchart for the equivalent modeling of an isogridstiffened cylinder is given in Figure 18.

\section{Nomenclature}

$E^{*}: \quad \quad$ Equivalent elastic modulus $(\mathrm{GPa})$

$E_{0}: \quad$ Baseline elastic modulus (GPa)

$\left(N_{\mathrm{cr}}\right)_{\text {imperfect }}$ : Global buckling load with initial imperfection $(\mathrm{kN})$

$\left(N_{\text {cr }}\right)_{\text {perfect }}$ : Global buckling load without initial imperfection $(\mathrm{kN})$

$t^{*}: \quad$ Equivalent thickness $(\mathrm{m})$

$t_{\text {eff }}: \quad$ Effective thickness (m)

$\gamma: \quad$ Knockdown factor.

\section{Data Availability}

The numerical data used to support the findings of this study are included within the article.

\section{Disclosure}

This paper was presented at the 8th European Conference for Aeronautics and Space Sciences Conference, Spain, Madrid, July 1-4, 2019.

\section{Conflicts of Interest}

The authors declare that there is no conflict of interest regarding the publication of this paper. 


\section{Acknowledgments}

This work was supported by research on the preceding technologies for geostationary satellite launch vehicle of the Korea Aerospace Research Institute (KARI), the Korea Space Launch Vehicle (KSLV-II) funded by the Ministry of Science and ICT (MSIT, Korea), and a research fund of Chungnam National University.

\section{References}

[1] F. Tornabene, R. Dimitri, and S. Brischetto, "High-order formulation for the mechanical analysis of laminated and latticed shells with complex geometries and materials," in Proceeding of Advances in Boundary Element and Meshless Techniques XX, Palermo, Italy, 2019.

[2] Y. Zhang, Z. Xue, L. Chen, and D. Fang, "Deformation and failure mechanisms of lattice cylindrical shells under axial loading," International Journal of Mechanical Sciences, vol. 51, no. 3, pp. 213-221, 2009.

[3] G. Totaro and Z. Gürdal, "Optimal design of composite lattice shell structures for aerospace applications," Aerospace Science and Technology, vol. 13, no. 4-5, pp. 157-164, 2009.

[4] J. P. Peterson, P. Seide, and V. I. Weingarten, Buckling of thinwalled circular cylinders, NASA SP-8007, 1968.

[5] M. W. Hilburger, "On the development of shell buckling Knockdown factors for stiffened metallic launch vehicle cylinders," in Proceeding of 2018 AIAA/ASME/ASCE/AHS/ASC Structures, Structural Dynamics and Materials Conference, Kissimmee, FL, USA, 2018.

[6] R. Khakimova, R. Zimmermann, D. Wilckens, K. Rohwer, and R. Degenhardt, "Buckling of axially compressed CFRP truncated cones with additional lateral load: experimental and numerical investigation," Composite Structures, vol. 157, pp. 436-447, 2016.

[7] M. W. Hilburger, "Developing the next generation shell buckling design factors and technologies," in Proceeding of 53rd AIAA/ASME/ASCE/AHS/ASC Structures, Structural Dynamics and Materials Conference, Honolulu, Hawaii, 2012.

[8] M. W. Hilburger, A. Lovejoy, R. Thornburgh, and C. Rankin, "Design and analysis of subscale and full-scale bucklingcritical cylinders for launch vehicle technology development," in Proceeding of 53rd AIAA/ASME/ASCE/AHS/ASC Structures, Structural Dynamics and Materials Conference, Honolulu, Hawaii, 2012.

[9] M. W. Hilburger, W. A. Waters, and W. T. Haynie, Buckling test results from the 8-foot-diameter orthogrid-stiffened cylinder test article TA01, NASA TP-2015-218785, 2015.

[10] A. E. Lovejoy, M. W. Hilburger, and N. W. Gardner, "Test and analysis of full-scale 27.5-diameter stiffened metallic launch vehicle cylinders," in Proceeding of 2018 AIAA/ASCE/AHS/ASC Structures, Structural Dynamics, and Materials Conference, Kissimmee, Florida, 2018.

[11] R. Degenhardt, A. Kling, R. Zimmermann, F. Odermann, and F. C. de Araújo, "Dealing with imperfection sensitivity of composite structures prone to buckling," in Advances in Computational Stability Analysis, IntechOpen, 2012.

[12] R. Khakimova, C. J. Warren, R. Zimmermann, S. G. P. Castro, M. A. Arbelo, and R. Degenhardt, "The single perturbation load approach applied to imperfection sensitive conical com- posite structures," Thin-Walled Structures, vol. 84, pp. 369377, 2014.

[13] M. F. Di Pasqua, R. Khakimova, S. G. P. Castro, M. A. Arbelo, A. Riccio, and R. Degenhardt, "The influence of geometrical parameters on the buckling behavior of conical shell by the single perturbation load approach," Applied Composite Materials, vol. 22, no. 4, pp. 405-422, 2015.

[14] M. A. Arbelo, R. Degenhardt, S. G. P. Castro, and R. Zimmermann, "Numerical characterization of imperfection sensitive composite structures," Composite Structures, vol. 108, pp. 295-303, 2014.

[15] A. Meurer, B. Kriegesmann, M. Dannert, and R. Rolfes, "Probabilistic perturbation load approach for designing axially compressed cylindrical shells," Thin-Walled Structures, vol. 107, pp. 648-656, 2016.

[16] H. Abramovich, Stability and Vibrations of Thin-Walled Composite Structures, Woodhead Publishing, 2017.

[17] H. N. R. Wagner, C. Hühne, and S. Niemann, "Robust knockdown factors for the design of axially loaded cylindrical and conical composite shells - Development and Validation," Composite Structures, vol. 173, pp. 281-303, 2017.

[18] H. N. R. Wagner, C. Hühne, and S. Niemann, "Constant single-buckle imperfection principle to determine a lower bound for the buckling load of unstiffened composite cylinders under axial compression," Composite Structures, vol. 139, pp. 120-129, 2016.

[19] H. N. R. Wagner and C. Hühne, "Robust knockdown factors for the design of cylindrical shells under axial compression: potentials, practical application and reliability analysis," International Journal of Mechanical Sciences, vol. 135, pp. 410-430, 2018.

[20] B. Wang, P. Hao, G. Li et al., "Optimum design of hierarchical stiffened shells for low imperfection sensitivity," Acta Mechanica Sinica, vol. 30, no. 3, pp. 391-402, 2014.

[21] R. R. Meyer, O. P. Harwood, M. B. Harmon, and J. I. Orlando, Isogrid Design Handbook, NACA CR-124075, 1973.

[22] J. - T. Yoo, Y. -S. Jang, and Y. -M. Yi, "Structural design and development of isogrid cylinder for propellant tank," in Proceeding of 56th International Astronautical Congress, Fukuoka, Japan, 2005.

[23] K. Tian, B. Wang, P. Hao, and A. M. Waas, "A high-fidelity approximate model for determining lower-bound buckling loads for stiffened shells," International Journal of Solids and Structures, vol. 148-149, pp. 14-23, 2018.

[24] S. G. P. Castro, R. Zimmermann, M. A. Arbelo, and R. Degenhardt, "Exploring the constancy of the global buckling load after a critical geometric imperfection level in thinwalled cylindrical shells for less conservative knock-down factors," Thin-Walled Structures, vol. 72, pp. 76-87, 2013.

[25] M. Deml and W. Wunderlich, "Direct evaluation of the 'worst' imperfection shape in shell buckling," Computer Methods in Applied Mechanics and Engineering, vol. 149, no. 1-4, pp. 201-222, 1997.

[26] W. Haynie, M. W. Hilburger, M. Bogge, M. Maspoli, and B. Kriegesmann, "Validation of lower-bound estimates for compression-loaded cylindrical shells," in Proceeding of 53rd AIAA/ASME/ ASCE/AHS/ASC Structures, Structural Dynamics and Materials Conference, Honolulu, HI, USA, 2012.

[27] S. G. P. Castro, R. Zimmermann, M. A. Arbelo, R. Khakimova, M. W. Hilburger, and R. Degenhardt, "Geometric imperfections and lower-bound methods used to calculate knock- 
down factors for axially compressed composite cylindrical shells," Thin-Walled Structures, vol. 74, pp. 118-132, 2014.

[28] C.-H. Sim, J.-S. Park, H.-I. Kim, Y.-L. Lee, and K. Lee, "Postbuckling analyses and derivations of knockdown factors for hybrid-grid stiffened cylinders," Aerospace Science and Technology, vol. 82-83, pp. 20-31, 2018.

[29] C.-H. Sim, H.-I. Kim, Y.-L. Lee, J.-S. Park, and K. Lee, “Derivations of knockdown factors for cylindrical structures considering different initial imperfection models and thickness ratios," International Journal of Aeronautical and Space Sciences, vol. 19, no. 3, pp. 626-635, 2018.

[30] C. Hühne, R. Rolfes, E. Breitbach, and J. Teßmer, "Robust design of composite cylindrical shells under axial compression - Simulation and validation," Thin-Walled Structures, vol. 46, no. 7-9, pp. 947-962, 2008.

[31] B. Wang, K. du, P. Hao et al., "Numerically and experimentally predicted knockdown factors for stiffened shells under axial compression," Thin-Walled Structures, vol. 109, pp. 13-24, 2016.

[32] S. C. White, P. M. Weaver, and K. C. Wu, "Post-buckling analyses of variable-stiffness composite cylinders in axial compression," Composite Structures, vol. 123, pp. 190-203, 2015.

[33] MATLAB, Curve Fitting Toolbox: User's Guide, 2017, https:// www.mathworks.com/help/curvefit/exponential.html. 